\title{
Psychiatric disorders in primary focal dystonia and in Parkinson's disease
}

\author{
This article was published in the following Dove Press journal: \\ Neuropsychiatric Disease and Treatment \\ 17 March 2011 \\ Number of times this article has been viewed
}

\section{Fernando MV Dias' \\ Arthur Kummer' \\ Flávia CP Doyle ${ }^{2}$ \\ Estefânia Harsányi' \\ Francisco Cardoso ${ }^{2}$ \\ Leonardo F Fontenelle ${ }^{3}$ \\ Antônio Lúcio Teixeira' \\ 'Neuropsychiatric Branch, ${ }^{2}$ Movement Disorders Clinic, Neurology Unit, University Hospital, Federal University of Minas Gerais, Belo Horizonte; ${ }^{3}$ Department of Psychiatry, Federal University of Rio de Janeiro, Rio de Janeiro, Brazil}

Correspondence: Antonio Lucio Teixeira Department of Internal Medicine, School of Medicine, University Hospital, Federal University of Minas, Av. Alfredo Balena, 190 Santa Efigênia,

Belo Horizonte, Brasil 30130-100

$\mathrm{Tel}+553134092651$

Fax +55313409265 I

Email altexr@gmail.com
Background: Primary focal dystonia and Parkinson's disease are movement disorders that have contrasting motor phenotypes. The aim of this study was to compare the frequency and the severity of psychiatric disorders in primary focal dystonia and Parkinson's disease.

Methods: Two groups of 30 patients matched by gender and age underwent a neurological and psychiatric assessment.

Results: Parkinson's disease patients were diagnosed with higher rates of major depression $(P=0.02)$ and generalized anxiety disorder $(P=0.02)$, and greater severity of depressive symptoms $(P=0.04)$, while patients with primary focal dystonia exhibited increased severity of obsessive-compulsive symptoms $(P=0.02)$.

Discussion: The difference in pathophysiology of primary focal dystonia and Parkinson's disease may explain the different psychiatric profiles of these two diseases. The increased frequency of affective symptoms in Parkinson's disease may be related to the fact that Parkinson's disease is a neurodegenerative disease marked by the loss of monoaminergic neurons which does not happen in primary focal dystonia.

Conclusion: The psychiatric profile differs in movement disorders with distinct neurobiological bases.

Keywords: focal dystonia, Parkinson's disease, neuropsychiatry, depression, obsessivecompulsive disorder

\section{Introduction}

The study of psychiatric comorbidities in movement disorders has provided meaningful insights into the pathophysiology of these conditions. For instance, the observation of an outbreak of obsessive compulsive disorder following epidemic encephalitis (Encephalitis lethargica) anticipated the role of the basal ganglia in human behavior. ${ }^{1}$ The relationship between Sydenham's chorea and obsessive compulsive disorder also reinforces such an idea. ${ }^{2}$ However, conflicting results and methodological issues prevent us from establishing adequate explanatory models for neuropsychiatric disorders.

To investigate whether distinctive psychiatric phenotypes are associated with dysfunction of specific corticosubcortical circuits, we propose the comparison of the frequency and severity of psychiatric disorders in two movement diseases with different pathophysiological features. Dystonia is a neurological hyperkinetic syndrome characterized by sustained muscular contractions that cause repetitive movements and abnormal postures. ${ }^{3,4}$ These motor disturbances may affect different body segments or involve a single body region, such as the hand, the neck, or the eyes. Dystonia is classified according to its etiology into primary, if no cause is identifiable, or secondary, when caused by trauma, drugs, and other defined mechanisms. ${ }^{3,4}$ There is a growing 
body of evidence linking genetic mutations and primary focal dystonia, ${ }^{3,4}$ which seems to originate from a dysfunction in the corticostriatal circuitry.

Conversely, parkinsonism is a hypokinetic syndrome characterized by bradykinesia, rigidity, rest tremor, and postural instability. Parkinson's disease is the main cause of parkinsonism. The disease is pathologically defined by neuronal loss, predominantly in the substantia nigra pars compacta, and the presence of Lewy bodies in the remaining neurons. ${ }^{5}$ However, it is currently known that neuronal loss extends far beyond the substantia nigra, and may include degeneration of regions such as the dorsal IX and $\mathrm{X}$ motor nucleus, the raphe nuclei, locus coeruleus, and porencephalic regions. ${ }^{6}$ In addition, Parkinson's disease is probably the result of several components acting together, including aging, genetic susceptibility, inflammatory processes, and environmental factors. ${ }^{7}$ Treatment with dopaminergic drugs improves clinical symptoms without modifying the course of the disease. Although the diagnosis of Parkinson's disease is based on motor signs, the nonmotor aspects of the disease are extremely common and disabling.,

The investigation of psychiatric disorders in focal dystonia and Parkinson's disease needs more consistent data. Studies that have systematically assessed psychiatric disorders in focal dystonia are scarce in the literature. ${ }^{9-11}$ Nevertheless, psychiatric comorbidities are frequently reported in these patients, and probably have a significant impact on clinical control and quality of life. ${ }^{10,11}$ Although there is controversy in the literature concerning the prevalence of psychiatric disorders in focal dystonia, it is well recognized that depression, anxiety, and sleep disturbances are more prevalent in Parkinson's disease patients than in the general population. ${ }^{7}$

The main objective of this study was to compare the frequency and the severity of psychiatric disorders in focal dystonia and Parkinson's disease. Our main hypothesis was that these two movement disorders differ in their profile of psychiatric symptoms and disorders. If both disorders contrast in terms of psychiatric profile, the distinct pathophysiology of focal dystonia and Parkinson's disease might explain this difference. The results of this research will contribute to the study of nonmotor symptoms of Parkinson's disease and, particularly, focal dystonia. This study might also improve our understanding of the role of certain brain structures, such as corticostriatal circuitry, in psychiatric disorders.

\section{Methods}

\section{Study design}

This was a cross-sectional study of patients diagnosed with focal dystonia or Parkinson's disease, and who were attending the Movement Disorders Clinic of the University Hospital, School of Medicine, Federal University of Minas Gerais.

Participants were invited to participate in this study in a consecutive manner. Considering that focal dystonia is a rare disease, focal dystonia patients were enrolled first. Afterwards, Parkinson's disease patients were consecutively recruited in order to match focal dystonia patients according to age and gender. None of them refused to participate.

Written informed consent was obtained from all the patients. Appropriate comprehension of the consent form by the participant and/or his/her companion was assured by the researchers. The study was approved by the ethics committee from the Federal University of Minas Gerais, which also approved the consent form. This research was conducted in accordance with the Declaration of Helsinki.

\section{Inclusion and exclusion criteria}

Patients diagnosed with focal dystonia or Parkinson's disease who signed the informed consent were included. Both diseases were diagnosed independently by two of the authors (FC and ALT) according to the current diagnostic criteria. ${ }^{12,13}$ Dementia, delirium, history of neurosurgery, and the presence of any other relevant neurological disease were taken as exclusion criteria. Dementia was diagnosed according to DSM-IV (Diagnostic and Statistical Manual of Mental Disorders, 4th Edition) criteria and according to the performance in the Mini Mental State Examination adapted for the Brazilian population. ${ }^{14}$ Delirium was diagnosed according to DSM-IV criteria.

\section{Recruitment and assessment}

Sixty patients (30 with Parkinson's disease and 30 with focal dystonia) were enrolled. Participants were invited to participate in the study just before their appointment at the University Hospital. All patients underwent a comprehensive neurologic examination conducted by ALT. Neurologic examination of Parkinson's disease patients included the Unified Parkinson's Disease Rating Scale (UPDRS), the Hoehn-Yahr Scale (HY), and the Schwab-England Scale of activities of daily living (SES). UPDRS is an instrument which assesses severity of nonmotor symptoms, motor signs, and impact on activities of daily living. The HY objectively evaluates stages of Parkinson's disease, and the SES is used to assess impact of Parkinson's disease on daily living activities.

The focal dystonia patients had primary focal dystonia. Primary dystonia, classically called idiopathic dystonia, refers to syndromes in which dystonia is the primary clinical manifestation and in which secondary causes have been 
carefully excluded. Ten patients presented with the cervical dystonia subtype, and 20 presented with the blepharospasm subtype.

All patients also underwent a psychiatric evaluation which included the MINI-Plus, ${ }^{15}$ an internationally validated structured clinical interview for psychiatric diagnosis according to DSM-IV, and psychometric scales, including the Yale-Brown Obsessive Compulsive Scale (YBOCS), ${ }^{16}$ the Beck Depression Inventory (BDI) ${ }^{17}$ the Hamilton Anxiety Rating Scale (HAM-A), ${ }^{18}$ and the Liebowitz Social Anxiety Scale (LS). ${ }^{19}$ These instruments were administered by the first two authors.

\section{Statistical analyses}

Comparisons between categorical variables among groups were performed using the Fisher's Exact test. The MannWhitney U test was used for continuous variables. All $P$ values were two-tailed, and a significance level of 0.05 was chosen. Statistical analysis was performed using the SPSS version 17.0 software.

\section{Results}

The Parkinson's disease and focal dystonia groups had the same distribution of gender (males 10, females 20) and age (mean \pm standard deviation $[S D] 59.3 \pm 11.1$ ). Patients did not differ in other demographic features (Table 1). Almost half the sample had other medical conditions. Severity of Parkinson's disease according to the UPDRS was moderate in most patients $(54.0 \pm 27.5)$. HY ranged from 1 to 4 , with a median of 2. Percentile ratings on the SES suggested relatively independent functioning of the patients $(78 \pm 12.7)$. Most Parkinson's disease patients were

Table I Demographic and clinical features of patients with primary focal dystonia and Parkinson's disease

\begin{tabular}{|c|c|c|c|}
\hline & $\begin{array}{l}\text { Primary focal } \\
\text { dystonia } \\
(n=30)\end{array}$ & $\begin{array}{l}\text { Parkinson's } \\
\text { disease } \\
(n=30)\end{array}$ & $P$ value \\
\hline Gender (M/F) & $10 / 20$ & $10 / 20$ & 1.00 \\
\hline $\begin{array}{l}\text { Age, years, } \\
(\text { mean } \pm S D)\end{array}$ & $59.3 \pm 11.1$ & $59.3 \pm 11.1$ & 1.00 \\
\hline $\begin{array}{l}\text { Educational level, } \\
\text { years, (mean } \pm S D \text { ) }\end{array}$ & $7.8 \pm 6.72$ & $5.63 \pm 3.91$ & 0.23 \\
\hline $\begin{array}{l}\text { Marital status, } \\
\text { married (\%) }\end{array}$ & $16(53.3)$ & $20(66.7)$ & 0.29 \\
\hline $\begin{array}{l}\text { Age of disease onset, } \\
\text { years, (mean } \pm S D)\end{array}$ & $49.2 \pm 12.0$ & $50.6 \pm 11.2$ & 0.69 \\
\hline $\begin{array}{l}\text { Duration of symptoms, } \\
\text { years, (mean } \pm S D \text { ) }\end{array}$ & $8.7 \pm 4.16$ & $10.0 \pm 3.73$ & 0.11 \\
\hline $\begin{array}{l}\text { Other medical } \\
\text { conditions, (\%) }\end{array}$ & $16(53.3)$ & I $5(50.0)$ & 0.79 \\
\hline
\end{tabular}

Abbreviations: SD, standard deviation; M, male; F, female. using levodopa at a mean dose of $562.9 \pm 253.6 \mathrm{mg} /$ day (Table 2).

All patients with focal dystonia had been treated with botulinum toxin at least once before inclusion in the study. All patients but one were still using botulinum toxin. The patient who was no longer using botulinum toxin had had its use interrupted two years earlier. Focal dystonia patients currently using botulinum toxin had been doing so for $4.8 \pm 2.7$ years. None of the focal dystonia patients were using antidepressants or benzodiazepines. Psychoactive medications used by focal dystonia and Parkinson's disease patients are shown in Table 2.

According to the MINI-Plus, patients with Parkinson's disease showed a higher frequency of current major depressive disorder $(P=0.02)$ and generalized anxiety disorder $(P=0.02)$ than focal dystonia patients (Table 3$)$. The severity of depressive symptoms was also higher in patients with PD in comparison with focal dystonia $(P=0.04)$, according to the BDI (Table 4). The frequency of social phobia, as well as the severity of social anxiety, was remarkably high in both groups (Tables 3 and 4). The difference in the frequency of obsessive compulsive disorder between the groups did not reach statistical significance. However, patients with focal dystonia scored higher on the YBOCS $(P=0.02)$.

\section{Discussion}

In this research, the results suggest that patients with movement disorders may show different patterns of psychiatric disorders and symptoms. Patients with Parkinson's disease are more prone to suffer from major depression and generalized anxiety disorder. By contrast, it is possible that obsessivecompulsive symptoms are more frequent in patients with focal dystonia.

Our finding of a higher frequency of major depressive disorder in Parkinson's disease differs from the study by

Table 2 Psychotropic medications of patients with Parkinson's disease and focal dystonia $(n=30)$

\begin{tabular}{ll}
\hline Psychoactive medications in PD & Frequency (\%) \\
\hline L-Dopa & $25(83.3 \%)$ \\
Dopaminergic agonist & $12(40.0 \%)$ \\
Anticholinergic drugs & $12(40.0 \%)$ \\
Amantadine & $11(36.7 \%)$ \\
COMT inhibitors & $3(10.0 \%)$ \\
Antidepressants & $14(46.7 \%)$ \\
Benzodiazepines & $5(16.7 \%)$ \\
Psychoactive medications in FD & Score (mean \pm SD) \\
Carbamazepine & $\mathrm{I}(3.3 \%)$ \\
Anticholinergic & $2(6.6 \%)$ \\
\hline
\end{tabular}

Note: *Proportions exceed $100 \%$ because most patients with PD are in polypharmacy. Abbreviations: COMT, catechol-O-methyltransferase; FD, focal dystonia; PD, Parkinson's disease; SD, standard deviation. 
Table 3 Frequency of current psychiatric diagnosis in patients with primary focal dystonia and Parkinson's disease

\begin{tabular}{|c|c|c|c|}
\hline & $\begin{array}{l}\text { Primary focal } \\
\text { dystonia } \\
(n=30)\end{array}$ & $\begin{array}{l}\text { Parkinson's } \\
\text { disease } \\
(n=30)\end{array}$ & $P$ value \\
\hline $\begin{array}{l}\text { Major depressive } \\
\text { disorder (\%) }\end{array}$ & $5(16.7)$ & $13(43.3)$ & 0.02 \\
\hline Dysthymia (\%) & $2(6.7)$ & $4(13.3)$ & 0.39 \\
\hline $\begin{array}{l}\text { Generalized anxiety } \\
\text { disorder (\%) }\end{array}$ & $4(13.3)$ & $12(40)$ & 0.02 \\
\hline Panic disorder (\%) & $0(0.0)$ & $2(6.7)$ & 0.15 \\
\hline Social phobia (\%) & $15(50)$ & $13(43.3)$ & 0.60 \\
\hline Specific phobia (\%) & $3(10)$ & $5(16.7)$ & 0.65 \\
\hline Hypochondria (\%) & $3(10)$ & $0(0.0)$ & 1.00 \\
\hline $\begin{array}{l}\text { Body dysmorphic } \\
\text { disorder (\%) }\end{array}$ & $2(6.7)$ & $0(0.0)$ & 1.00 \\
\hline $\begin{array}{l}\text { Obsessive compulsive } \\
\text { disorder (\%) }\end{array}$ & $4(13.3)$ & I (3.3) & 0.16 \\
\hline Psychotic disorders (\%) & I (3.3) & $4(13.3)$ & 0.16 \\
\hline Tobacco dependence (\%) & $6(20)$ & $2(6.6)$ & 0.13 \\
\hline Alcohol abuse (\%) & $3(10.0)$ & $0(0)$ & 0.08 \\
\hline
\end{tabular}

Miller et al who did not find any significant difference in the prevalence and the severity of depressive symptoms among patients with Parkinson's disease, dystonia (focal, segmental, and generalized dystonia), and essential tremor. ${ }^{20}$ These conflicting results can be partly explained by differences in methods. In the study by Miller et al, the groups differed in age, gender, and symptom duration. In addition, these authors used the BDI rather than a structured clinical interview for psychiatric diagnosis of depression. By contrast, Lauterbach et al observed that atypical depression was more frequent in Parkinson's disease than in dystonia. ${ }^{21}$ However, a recruitment bias might have interfered with their results, because patients with dystonia were attending a support

Table 4 Scores of patients with primary focal dystonia and Parkinson's disease in psychopathological scales

\begin{tabular}{llll}
\hline & $\begin{array}{l}\text { Primary focal } \\
\text { dystonia } \\
(\mathbf{n}=\mathbf{3 0})\end{array}$ & $\begin{array}{l}\text { Parkinson's } \\
\text { disease } \\
(\mathbf{n}=\mathbf{3 0})\end{array}$ & P value \\
\hline $\begin{array}{l}\text { Beck Depression Inventory, } \\
\text { (mean } \pm \text { SD) }\end{array}$ & $15.0 \pm 13.1$ & $20.8 \pm 12.9$ & 0.04 \\
$\begin{array}{l}\text { Hamilton Anxiety Rating } \\
\text { Scale, (mean } \pm \text { SD) }\end{array}$ & $13.8 \pm 11.1$ & $17.1 \pm 10.7$ & 0.22 \\
$\begin{array}{l}\text { Liebowitz Social Anxiety } \\
\text { Scale - anxiety, (mean } \pm \text { SD) } \\
\text { Liebowitz Social Anxiety }\end{array}$ & $28.5 \pm 19.9$ & $28.1 \pm 17.2$ & 0.93 \\
$\begin{array}{l}\text { Scale - avoidance, } \\
\text { (mean } \pm \text { SD) }\end{array}$ & $23.6 \pm 19.6$ & 2.4 & 0.42 \\
$\begin{array}{l}\text { Yale-Brown Obsessive } \\
\begin{array}{l}\text { Compulsive Scale, } \\
\text { (mean } \pm \text { SD) }\end{array}\end{array}$ & $3.3 \pm 7.3$ & $0.4 \pm 2.2$ & 0.02 \\
\hline
\end{tabular}

Abbreviation: $\mathrm{SD}$, standard deviation. group. ${ }^{22}$ It is worth mentioning that although $46.7 \%$ of our Parkinson's disease patients were taking antidepressant drugs, this fact did not prevent us from finding increased rates of major depression in this group. Therefore, it is possible that the increased frequency of major depression in Parkinson's disease may be related to the fact that Parkinson's disease is a neurodegenerative disease marked by the loss of monoaminergic neurons. This severe neurobiological change may make Parkinson's disease resistant to pharmacological treatment with antidepressants. Besides, the proinflammatory state found in Parkinson's disease patients could make these patients more vulnerable to depression. ${ }^{22-24}$ In focal dystonia, an inflammatory state has not been described, and the changes observed in the brains of dystonic patients are uncovered only by functional neuroimaging. ${ }^{25}$ Moreover, botulinum toxin may display antidepressant properties. ${ }^{26}$ Given that focal dystonia patients were treated with botulinum toxin at least once, this could have influenced the frequency of major depression in our focal dystonia sample.

For a long time, focal dystonia had been considered a disorder triggered by a psychological condition, due to the bizarre nature of its symptoms, the variation of its intensity, and the sensorial tricks to disguise the movements. ${ }^{4}$ Nowadays, a genetic basis for the disease and the involvement of brain structures are recognized. ${ }^{4,27}$ Interestingly, the neurobiological basis proposed for focal dystonia by some authors is the same underlying obsessive compulsive disorder. ${ }^{28}$ Indeed, the presence of obsessive and avoidant personality features has been found in focal dystonia, ${ }^{29}$ while the presence of such personality traits in Parkinson's disease remains open to debate. ${ }^{1}$ In our study, the prevalence of obsessive compulsive disorder was not significantly different between the groups, and the differences in YBOCS scores in favor of focal dystonia are within the limits of subclinical obsessive compulsive disorder. Although a higher frequency of obsessive compulsive disorder and obsessive compulsive symptoms has also been found by some authors, ${ }^{28,30,31}$ this is still controversial. ${ }^{21,32-34}$

The frequency of other psychiatric disorders did not differ between the groups. Social phobia disorder compromised half the patients with focal dystonia and $43 \%$ of the patients with Parkinson's disease, according to the MINI-Plus. Accordingly, focal dystonia and Parkinson's disease patients scored high in LS components, namely anxiety and avoidance. Previous studies have also observed an increased frequency of social anxiety disorder in both focal dystonia ${ }^{35}$ and Parkinson's disease. ${ }^{36}$ Nevertheless, in a study conducted by Lauterbach et al, social phobia and generalized anxiety disorder were more frequent in patients with dystonia, while 
panic disorder and simple phobia were more prevalent in Parkinson's disease. ${ }^{37}$ Again, important differences in methods may explain these contrasting results. In the study from Lauterbach et al, a quarter of the patients had generalized dystonia, and apparently none of them had ever used botulinum toxin. ${ }^{21,37}$ Also, dystonia group was younger and had more females. In addition, these authors used a structured interview based on DSM-III (Diagnostic and Statistical Manual of Mental Disorders, 3rd Edition) criteria. Finally, both groups were recruited from tertiary centers and included a small number of subjects $(\mathrm{n}=28)$. Interestingly, they observed that generalized anxiety disorder and social phobia tended to develop before dystonia onset, which is in favor of a biological basis of these psychiatric disorders in this context. A common inherited genetic basis might have a role in some movement disorders, and their comorbid psychiatric disorders, through epigenetic mechanisms. ${ }^{38,39}$ Dysfunction in frontostriatal circuitry, which responds to the motor symptoms and alters affective processes through limbic circuitry, may provide a neurobiological explanation for the high prevalence of social phobia in patients suffering from focal dystonia and Parkinson's disease. ${ }^{40}$ Parkinson's disease and focal dystonia also present some clinical features which are esthetically compromising and rather dysfunctional.

Considering the existence of these patients in a society where appearance is essential to achieve personal and professional success, social withdrawal and anxiety about social interaction are perhaps understandable. ${ }^{41}$ In animal studies, social phobic behavior can emerge in extremely aversive environments, supporting this hypothesis. ${ }^{42}$

Our study has some clear limitations. Our sample was recruited from a movement disorders clinic, and thus may not be representative of the general population. The sample size might also be responsible for the lack of significant differences regarding some psychiatric disorders, such as panic disorder, obsessive compulsive disorder, psychosis, and substance abuse. Both groups also differed in the use of psychotropic drugs. One additional factor restricting the generalization of our findings was the somewhat atypical profile of patients with Parkinson's disease (ie, lower mean age and increased numbers of females) which were selected for the sake of comparison with the focal dystonia group. The lack of scales assessing the severity and impact of focal dystonia is another limitation. In Parkinson's disease, the manifestation of depressive and anxious symptoms varied according to the severity and the stages of the disease. Because the severity of focal dystonia was not assessed, it was not possible to evaluate the effect of the severity of disease on psychiatric comorbidity when comparing focal dystonia and Parkinson's disease. Other relevant missing information was the age at onset of the psychiatric disorder. Unfortunately, most patients could not remember the onset of their psychiatric symptoms, possibly due to the long duration of the disease and their limited educational level. Of note, the low educational level is explained by the fact that Brazil is a developing country, and a significant proportion of the elderly people could not attend school.

It would be interesting to assess pain in these patient groups. Because the prevalence of pain seems to be different in these diseases, this could have influenced the observed frequency of some psychiatric disorders. Finally, the explanatory models of both disorders still have some problematic points. For instance, it is known that patients with Parkinson's disease can also suffer from dystonia, which is a clinical determinant of health-related quality of life in these patients. ${ }^{43}$ The equal proportion of males and females and the similarities in other demographic variables, controlling for gender- and age-related differences in the prevalence of psychiatric disorders, may be considered strengths of the present study.

\section{Conclusion}

In conclusion, our study reinforces the clinical observation that movement disorders with different neurobiological bases may differ in respect of psychological and/or psychiatric profile. Moreover, because there is still a gap in the literature, the investigation of psychiatric disorders in focal dystonia may indicate the brain area involved in its pathophysiology. This study also suggests that physicians must be aware that the frequency of psychiatric disorders, such as depression and anxiety, is high in both diseases. Physicians who assist Parkinson's disease and focal dystonia patients must diagnose and treat such symptoms in order to provide a better quality of life for the patients.

\section{Acknowledgments}

This work was partly funded by FAPEMIG, Brazil.

\section{Disclosure}

The authors report no conflicts of interest in this work.

\section{References}

1. Kummer A, Teixeira AL. Parkinson's disease and obsessive-compulsive phenomena: A systematic review. Curr Psychiatry Rev. 2009;5(1): 55-61.

2. Maia DP, Teixeira AL, Cunningham MC, Cardoso F. Obsessive compulsive behavior, hyperactivity, and attention deficit disorder in Sydenham chorea. Neurology. 2005;24;64(10):1799-801.

3. Defazio G, Abbruzzese G, Livrea P, Berardelli A. Epidemiology of primary dystonia. Lancet Neurol. 2004;3(11):673-678.

4. Carvalho Aguiar PM, Ozelius LJ. Classification and genetics of dystonia. Lancet Neurol. 2002;1(5):316-325. 
5. Calne D. A definition of Parkinson's disease. Parkinsonism Relat Disord. 2005;11 Suppl 1:S39-S40.

6. Braak H, Del Tredici K, Rüb U, de Vos RAI, Jansen Steur EN, Braak E. Staging of brain pathology related to sporadic Parkinson's disease. Neurobiol Aging. 2003;24(2):197-211.

7. Kummer A, Teixeira AL. Neuropsychiatry of Parkinson's disease. Arq Neuropsiquiatr. 2009;67(3B):930-939.

8. Scalzo P, Kummer A, Cardoso F, Teixeira AL. Depressive symptoms and perception of quality of life in Parkinson's disease. Arq Neuropsiquiatr. 2009;67(2A):203-208.

9. Dias FMV, Doyle F, Kummer A, Cardoso F, Fontenelle LF, Teixeira AL. Frequency of psychiatric disorders in blepharospasm does not differ from hemifacial spasm. Acta Neuropsychiatr. 2010;22(5):223-227.

10. Gündel H, Wolf A, Xidara V, et al. High psychiatric comorbidity in spasmodic torticollis: A controlled study. JNerv Ment Dis. 2003;191(7): 465-473.

11. Hall TA, McGwin G Jr, Searcey K, et al. Health-related quality of life and psychosocial characteristics of patients with benign essential blepharospasm. Arch Ophthalmol. 2006;124(1):116-119.

12. Hughes TA, Ross HF, Mindham RH, Spokes EG. Mortality in Parkinson's disease and its association with dementia and depression. Acta Neurol Scand. 2004;110(2):118-123.

13. Fahn S, Eldridge R. Definition of dystonia and classification of the dystonic states. Adv Neurol. 1976;14:1-5.

14. Brucki SM, Nitrini R, Caramelli P, Bertolucci PH, Okamoto IH. Suggestions for utilization of the Mini-Mental State Examination in Brazil. Arq Neuropsiquiatr. 2003;61(3B):777-781.

15. Amorim P. Mini International Neuropsychiatric Interview (MINI): validation of a short structured diagnostic psychiatric interview. Rev Bras Psiquiatr. 2000;22(3):106-115.

16. Araújo LA. Escalas de avaliação de transtorno obsessivo compulsivo em adultos. [Rating Scales for Obsessive Compulsive Disorder in Adults.] Rev Psiq Clin. 1998;25(6):307-309.

17. GorensteinC,AndradeL. BeckDepression Inventory:psychometric properties of the Portuguese version. Rev Psiquiatr Clin. 1998;25(5):245-250.

18. Kummer A, Cardoso F, Teixeira AL. Generalized anxiety disorder and the Hamilton Anxiety Rating Scale in Parkinson's disease. Arq Neuropsiquiatr. 2010;68(4):495-501.

19. Terra MB, Barros HMT, Stein AT, et al. Internal consistency and factor structure of the Portuguese version of the Liebowitz Social Anxiety Scale among alcoholic patients. Rev Bras Psiquiatr. 2006;28(4):265-269.

20. Miller KM, Okun MS, Fernandez HF, Jacobson CE, Rodrigues RL, Bowers D. Depression symptoms in movement disorders: Comparing Parkinson's disease, dystonia, and essential tremor. Mov Disord. 2007;22(5):666-672.

21. Lauterbach EC, Freeman A, Vogel RL. Differential DSM-III psychiatric disorder prevalence profiles in dystonia and Parkinson's disease. J Neuropsychiatry Clin Neurosci. 2004;16(1):29-36.

22. Kummer A, Teixeira AL. Depressive disorders in Parkinson's disease may be due to a shared immune-mediated neurodegenerative process. Med Hypotheses. 2008;70(1):201-202.

23. Scalzo P, Kümmer A, Cardoso F, Teixeira AL. Serum levels of interleukin-6 are elevated in patients with Parkinson's disease and correlate with physical performance. Neurosci Lett. 2010;468(1):56-58.

24. Scalzo P, Kümmer A, Cardoso F, Teixeira AL. Increased serum levels of soluble tumor necrosis factor-alpha receptor-1 in patients with Parkinson's disease. J Neuroimmunol. 2009;216(1-2):122-125.
25. Tanabe LM, Kim CE, Alagem N, Dauer WT. Primary dystonia: Molecules and mechanisms. Nat Rev Neurol. 2009;5(11):598-609.

26. Beer K. Cost effectiveness of botulinum toxins for the treatment of depression: Preliminary observations. J Drugs Dermatol. 2010;9(1): 27-30.

27. Munts AG, Koehler PJ. How psychogenic is dystonia? Views from past to present. Brain. 2010;133(5):1552-1564.

28. Cavallaro R, Galardi G, Cavallini MC, et al. Obsessive compulsive disorder among idiopathic focal dystonia patients: an epidemiological and family study. Biol Psychiatry. 2002;52(4):356-361.

29. Lencer R, Steinlechner S, Stahlberg J, et al. Primary focal dystonia: Evidence for distinct neuropsychiatric and personality profiles. J Neurol Neurosurg Psychiatry. 2009;80(10):1176-1179.

30. Bihari K, Hill JL, Murphy DL. Obsessive-compulsive characteristics in patients with idiopathic spasmodic torticollis. Psychiatry Res. 1992; 42(3):267-272.

31. Wenzel T, Schnider P, Wimmer A, Steinhoff N, Moraru E, Auff E. Psychiatric comorbidity in patients with spasmodic torticollis. J Psychosom Res. 1998;44(6):687-690.

32. Munhoz RP, Teive HA, Della Coletta MV, et al. Frequency of obsessive and compulsive symptoms in patients with blepharospasm and hemifacial spasm. Arq Neuropsquiatr. 2005;63(2A):213-216.

33. Fabbrini G, Berardelli I, Moretti G, et al. Psychiatric disorders in adultonset focal dystonia: A case-control study. Mov Disord. 2010;25(4): 459-465.

34. Pacheco PG, Nascimento PM, Lauterbach EC, et al. Obsessivecompulsive symptoms among patients with blepharospasm and hemifacial spasm. CNS Spectrums. In press.

35. Gündel H, Wolf A, Xidara V, Busch R, Ceballos-Baumann AO. Social phobia in spasmodic torticollis. J Neurol Neurosurg Psychiatry. 2001;71(4):499-504.

36. Kummer A, Cardoso F, Teixeira AL. Frequency of social phobia and psychometric properties of the Liebowitz social anxiety scale in Parkinson's disease. Mov Disord. 2008;23(12):1739-1743.

37. Lauterbach EC, Freeman A, Vogel RL. Correlates of generalized anxiety and panic attacks in dystonia and Parkinson disease. Cogn Behav Neurol. 2003;16(4):225-233.

38. Hess CW, Raymond D, Aguiar PC, et al. Myoclonus-dystonia, obsessive-compulsive disorder, and alcohol dependence in SGCE mutation carriers. Neurology. 2007;68(7):522-524.

39. Haque FN, Gottesman II, Wong AH. Not really identical: Epigenetic differences in monozygotic twins and implications for twin studies in psychiatry. Am J Med Genet C Semin Med Genet. 2009;151C(2): 136-141.

40. Alexander GE, Crutcher MD, DeLong MR. Basal ganglia-thalamocortical circuits: Parallel substrates for motor, oculomotor, "prefrontal" and "limbic" functions. Prog Brain Res. 1990;85:119-146.

41. Kessler RC. The impairments caused by social phobia in the general population: Implications for intervention. Acta Psychiatr Scand. 2003; 417 (Suppl):19-27.

42. Guitton MJ, Klin Y, Dudai Y. Taste-dependent sociophobia: When food and company do not mix. Behav Brain Res. 2008;191(2):148-152.

43. Winter Y, von Campenhausen S, Popov G, et al. Social and clinical determinants of quality of life in Parkinson's disease in a Russian cohort study. Parkinsonism Relat Disord. 2010;16(4):243-248.
Neuropsychiatric Disease and Treatment

\section{Publish your work in this journal}

Neuropsychiatric Disease and Treatment is an international, peerreviewed journal of clinical therapeutics and pharmacology focusing on concise rapid reporting of clinical or pre-clinical studies on a range of neuropsychiatric and neurological disorders. This journal is indexed on PubMed Central, the 'PsycINFO' database and CAS, and is the official

\section{Dovepress}

journal of The International Neuropsychiatric Association (INA). The manuscript management system is completely online and includes a very quick and fair peer-review system, which is all easy to use. Visit http://www.dovepress.com/testimonials.php to read real quotes from published authors. 